\title{
New RN residency program to improve clinical competency, confidence, and socialization skills of novice nurses
}

\author{
Kimberly H. Kim ${ }^{* 1}$, Andrew Young Lee ${ }^{2}$, Lynn Eudey ${ }^{3}$, Karen Lounsbury ${ }^{4}$, Patrice Wede ${ }^{5}$ \\ ${ }^{1}$ Department of Nursing and Health Sciences, California State University East Bay, California, United States \\ ${ }^{2}$ College of Engineering, California Polytechnic State University, San Luis Obispo, California, United States \\ ${ }^{3}$ Department of Statistics, California State University East Bay, California, United States \\ ${ }^{4}$ Nursing Education, Valley Care Health System, Livermore, California, United States \\ ${ }^{5}$ Sutter Eden Medical Center, Castro Valley, California, United States
}

Received: February 7, 2015

DOI: $10.5430 /$ jnep.v5n6p50
Accepted: March 25, 2015

Online Published: March 30, 2015

\begin{abstract}
Objective: The transition to practice experience provides a useful process to integrate nursing knowledge, skills, and attitudes of newly graduated nurses before they assume the professional nurses' roles. The study examined the levels of perceived clinical competency, confidence, and professional role development skills of 114 culturally diverse novice nurses enrolled in 12-15 weeks of a collaborative RN residency program at a state funded California university during academic years 2009-2013.

Methods: Descriptive pre- and post-program measures study assessed core competency and confidence of participants before and after the residency program using three instruments; a modified quality and safety education for nurses (QSEN) competency questionnaire, Preceptorship Experience Questionnaire, and Graduate Nurse Survey.

Results: Compared to the pre-program sum, participants report to perceive the significantly higher levels of the post-program sum of competency skills in applying QSEN concepts and nursing process cycles that include assessment, planning, implementation, and evaluation as well as professional role development. Interestingly, participants report to feel it is very important to develop a trusting relationship with their preceptor and positive relationship with staff nurses. Participants also report to perceive the higher level of confidence in carrying out nursing care at the end of the program.

Conclusions: Findings suggest that newly graduated nurses perceive the increased levels of clinical competency and confidence on their self-administered report after participating in the RN residency program.
\end{abstract}

Key Words: RN residency program, Transition to practice, New graduate nurses, Competency skills, Confidence, Quality and safety education for nurses, Nursing process cycles

\section{INTRODUCTION}

Recent evidence shows that newly graduated nurses experience difficulty securing professional nursing positions. The primary barrier to employment for new nurses is competi- tion with experienced nurses as well as their lack of clinical work experiences. During periods of economic recession, experienced nurses tend to return to the workforce, increase their work hours and delay their retirement. The economic

\footnotetext{
*Correspondence: Kimberly H. Kim; Email: kimberly.kim@csueastbay.edu; Address: Department of Nursing and Health Sciences, California State University East Bay, 25800 Carlos Bee Blvd. Hayward, United States.
} 
recession induced retired RNs to reenter nursing and working nurses to work more hours and delayed retirement, thus easing the projected RN shortage. ${ }^{[1]}$ This trend has led to newly licensed RN difficulty securing nursing positions in acute- or long-term care settings. Furthermore, clinical agencies might experience a high cost in preparing new nurses to perform competently after they graduate from nursing schools. As a result, hospitals prefer to hire experienced nurses and give fewer job openings available to new nurses. This trend in hiring decreases combined with increased nursing program graduation rates points to an increased number of newly licensed nurses without jobs. Long-term trends in healthcare indicate that, despite the recent economic recession, the nursing shortage is expected to intensify when baby boomers retire within 10-15 years. For this reason, it is essential for new nurses to remain in the nursing workforce, so they are readily available when the demand arises.

Newly graduated nurses often lack clinical skills needed to transition efficiently and safely from academics to bedside practice. For example, nurses at the acute care settings are caring for much sicker and more diverse patients with complicated health conditions under multifaceted healthcare delivery systems that require applications of intricate health informatics and technologies. Implementing transition experiences for newly licensed nurses might provide additional clinical experiences that would improve their nursing skills and reduce training time in their first job that would lead to a successful nursing career as beginning nurses. The new RN residency model could be collaboratively implemented with education and practice. Team-based residencies provided both an opportunity to improve collaboration and a model of patient-centered care ${ }^{[2]}$ and increased engagement with learning professional skills, communication, problem solving and critical thinking. ${ }^{[3]}$ As educators, they could design the appropriate residency curriculum and modules that could be used by clinical preceptors and new nurse preceptees. Clinical educators in practice could provide new nurses with planned orientation and qualified nurses to precept them.

The transition to practice experience provides a useful process to integrate knowledge, skills and attitudes of new nurses before they assume the professional nurse's role. Although long term effects of the turnover rates of the nurse residency program have not been reported, it remains well below the national average. ${ }^{[4]}$ The question is how competent new nurses feel while implementing the nursing processes and providing quality, safe patient care at the end of their residency experience. This study investigated levels of perceived clinical competency and confidence of newly graduated nurses that participated in a university-based $\mathrm{RN}$ residency program that was initiated and implemented by faculty at the university

Published by Sciedu Press from academic years 2009 to 2013

\section{Literature review}

Recent economic downturn has stabilized the nursing shortage in part of the country. Although this might be a temporary trend due to the unstable economy, it is worrisome as that exists within the midst of a nursing shortage. With nursing shortages in the US ${ }^{[5]}$ increasing to a predicted $36 \%$ by 2020 and projected retirements, the rising requirement of hiring new graduate nurses is imperative. ${ }^{[6,7]}$ When facing the significant challenges related to the transition from a student nurse to a newly licensed nurse, increasing numbers of new graduates felt unprepared and overwhelmed. ${ }^{[8-10]}$ On a grounded theory study, Mellor and Greenhill[11] noted that new nurses in transition to practice reported to have feelings of underprepared for practice, overwhelmed by responsibility, and often abandoned when clinical support did not occur. New graduates' increasing stress level and feelings of incompetence led to a higher potential for turnover ${ }^{[12]}$ which could be detrimental to providing safe patient care in clinical agencies. Kovner, Brewer, Fatehi, and Jun ${ }^{[13]}$ reported that approximately $17.5 \%$ of new nurses left their first job within one year of starting their work.

Due to the amount of education and supervision required by new graduates, their turnover costs were higher than those of experienced RNs. ${ }^{[7]}$ The expenses of training and orienting a new professional nurse in an acute care hospital might cost as high as $\$ 96,595$. $^{[14]}$ Since the phenomenon of new graduate turnover was very expensive to hiring organizations, well-designed residency programs that support the new graduate nurses' transition into practice were one of the approaches used to increase levels of satisfaction in and retention of new graduates. ${ }^{[6,8,9,14,15]}$ Scott, Engelke, and Swanson ${ }^{[16]}$ emphasized the importance of orientation in the first job in promoting new graduates' job satisfaction and retention; while Fiedler, Read, Lane, Hicks, and Jegier ${ }^{[4]}$ made a point of the leadership development in pursuing an advanced degree increased with longer employment of participants in their residency program. Banister, Bowen-Brady, and Winfrey ${ }^{[17]}$ reported that the transition program that utilized one on one mentor-mentee relationship had a zero rate of attrition and very low job turnover among graduates.

Literature identified several components that contributed to the success of residency programs. For example, the results of a 13-week structured, progressive orientation program that focused on development of critical thinking skills, patient care management, and enhancement of self-esteem directly influenced retention of new nurses. ${ }^{[18]}$ Besides teaching the knowledge and skills required for competence, Newhouse, Hoffman, Suflita, \& Hairston ${ }^{[19]}$ claimed that internship pro- 
grams for nurse graduates must support the socialization of nurses and their transition into the professional role. Furthermore, in preparation of employment at acute care settings, participants identified the developing nursing expertise, future expectations and communication as recommendations ${ }^{[20]}$ for the effective residency program.

New nurses might change their focus of learning during the residency program. Fink, Krugman, Casey, \& Goode ${ }^{[21]}$ argued that new graduate nurses primarily focused on internal issues, such as their clinical practice, personal identity and coping strategies during the first six months; and became more external, shifting to patient care and the health care team, and advancing their learning during the second six months. Because the new graduate nurses' transition usually taking place over months, Bratt ${ }^{[8]}$ predicted that a successful residency program would provide a long-term psychosocial support system via well-trained preceptors and mentors. On an integrative review, Rush and colleagues ${ }^{[22]}$ found that the presence of a formal new graduate transition program resulted in good retention and improved competency: The stronger evidence suggested that new graduate education should focus on practical skill development, peer support opportunities, healthy work environments, and formal preceptor training where new nurses would receive ongoing support from their preceptors/mentors.

Mentorship or preceptorship plays an essential part in residency programs. The literature recognized that mentorship supported new graduates by reducing their stress and promoting their positive self-esteem ${ }^{[23]}$ and confidence, so as to facilitate their transition into the workplace and social culture of the organization. ${ }^{[24]}$ Furthermore, to facilitate transition to practice and develop the clinical leadership collaborative in minority students, Banister, Bowen-Brady, and Winfrey ${ }^{[17]}$ identified key components that were rated high by mentees and mentors: Aspects of mentees rated highest by mentors included courteous and professional manner, ability to communicate and get along with others, preparation for meetings, and fully utilizing their time with mentors. And, aspects of mentors rated highest by mentees include warmth, encouragement, and willingness to listen; enthusiasm for nursing and how they sparked the mentee's interest; and clarity regarding expectations for mentees and how they pushed mentees to achieve high standards. ${ }^{[17]}$ Spending adequate time for regular face-to-face meetings to establish a successful relationship between mentor and resident-mentee was crucial to the success of mentorship.

In addition to discussing the components of residency programs, the literature presents sporadic reports of overall outcomes from individualized programs. In general, retention increased and new graduates appreciated the support received during their professional transition. ${ }^{[25-28]}$ An internship program of Children's Memorial Hospital in Chicago that included classroom and skills lab learning, precepted orientation, professional transitioning sessions, and clinical learning exchanges contributed to increasing nursing recruitment and retention, significant cost savings, and increasing nursing satisfaction. ${ }^{[29,30]}$ In another study of one-year outcomes of a post-baccalaureate residency program, Williams and colleagues ${ }^{[31]}$ found that participants' job satisfaction improved on study variables such as, professional opportunities and control-responsibility at 12 months. Bratt and colleagues ${ }^{[12]}$ also claimed that perceptions of the work environment particularly job satisfaction and job stress were found to be most influential.

The effects of residency programs on improving the clinical competency and reducing stress level of new graduate nurses were demonstrated in several studies. Based on an analysis of outcomes from The University Health system Consortium (UHC) and the American Association of Colleges of Nursing (AACN) residency program, the residents demonstrated improvement in their skills and their ability to organize and prioritize work as well as communicating with the care team, patients, and families; and providing clinical leadership on the unit where they worked. Stress scores and turnover decreased. ${ }^{[7]}$ In one year follow up residency program at Las Vegas hospitals in Nevada, Kowalski and Cross ${ }^{[32]}$ concluded that the clinical competency levels of 55 nurse residents improved throughout the program, and findings also suggested that participants decreased the sense of threat and improved communication and leadership skills.

The outcomes of previous studies indicate that new graduate nurses improved their clinical competency, job satisfaction, and reduced their stress level, ultimately increasing retention through well-designed residency programs. Furthermore, the university-based new RN residency program might demonstrate the potential benefits to address the nursing shortage, reduce turnover and recruitment costs and provide new graduate nurses an advantage in improving their competency and confidence as well as seeking their first clinical positions.

\section{METHODS AND DESIGN}

This descriptive study assessed the levels of perceived clinical competency skills and confidence of culturally diverse new graduate nurses enrolled in a collaborative RN residency program at a state funded California University. The study specifically addressed the following research questions: (a) What are the reported indicators of clinical competency skills of novice nurses that participated in the new RN residency program? (b) What are the reported indicators of 
clinical confidence of novice nurses that participated in the new RN residency program? (c) How competent do new nurses feel implementing QSEN core competency skills? (d) How competent do new nurses feel about implementing the nursing process cycles? and (e) Is there a relationship between demographic variables (i.e., type of program attended and clinical placement sites) and self-reported QSEN competency?

The Bay Area collaborative residency project, initiated and implemented by the primary author, was designed to offer 12-15 weeks of additional clinical experience for newly licensed nurses to transition successfully into the workforce. The regional collaborative partners included ten acute care hospitals, three skilled nursing facilities, two community and tele-health clinics, and a workforce investment board in the San Francisco Bay area. Of the 238 residency participants that met the application criteria and attended the residency program, a sample of 114 completed the questionnaires and participated in the study during academic years 2009-2013. Participants attended two hours of seminar and the minimum of 24 hours of clinical practice each week, completing a total of 312 hours of post-baccalaureate credits; 288 hours of clinical practice and 24 hours of seminar credits. In seminars, students learned principles and concepts on management of responsibilities, communication, evidence-based practice, cultural care, resume writing and interviewing skills, ostomy and wound care, IV management, etc. In clinical practice, each participant was assigned to a preceptor who received the formal preceptorship training prior to beginning the residency practicum. Preceptors were selected by unit managers based on their quality and availability, and then the agency coordinator shared preceptor names and contact information with the university faculty coordinator that worked with students.

Application criteria for the $\mathrm{RN}$ residency program included newly licensed nurses that graduated from the nursing programs in the San Francisco (SF) Bay Area, received the California State RN licenses within two years, and provided one page appealing purpose statements and three professional letters of recommendations. They also submitted transcripts, health documents, certified background information, picture identification (ID), and appropriate nursing diploma as required by the university admission. Of the participants, ten additional nurses were included as non-SF Bay Area participants as additional grant funding was available to cover their education cost. They met the same application criteria. Prior to conducting the research, the university Institutional Review Board (IRB) approved the study. Participants were instructed that it was voluntary and their decision had no effect on continued clinical practice and residency seminars, or affect any benefits that they received or might wish to receive in the future from any agency. However they were also informed that they must complete clinical evaluation forms by both themselves and their preceptor in order to receive the university education credits which consisted of two units of seminar and eight units of clinical practicum. Questionnaires and open-ended qualitative questions were used in post-baccalaureate seminar courses before, during, and after the residency program.

\section{Measurements}

Data were collected using three instruments: Modified version of quality and safety education for nurses (QSEN) Competency Questionnaire, ${ }^{[33,34]}$ Preceptorship Experience Questionnaire, ${ }^{[35]}$ and Graduate Nurse Survey. ${ }^{[36]}$ The modified version of QSEN competency instrument was a selfadministered 36-item questionnaire evaluating participants' core nursing knowledge, skills, and attitude. This instrument was developed and organized from QSEN concepts and AACN competency guidelines, and content analyzed by the author and QSEN residency faculty in the Bay Area. ${ }^{[33]}$ Three clinical educators and faculty teaching nursing courses reviewed the questionnaire which was then revised according to their recommendations. Evaluation of the questionnaire by the nursing team helped to establish content validity. The QSEN Competency Questionnaire completed by the participants at pre- and post-program was divided into seven areas of competency: Patient centered care, safety, evidence based practice, teamwork, professionalism, quality improvement, and informatics. For example, the patient centered care items consist of Item 1 (conducting comprehensive physical and psychosocial health history that includes patient's perspective and considers cultural, spiritual and social considerations) to Item 9 (establishing rapport with patients and family members). The informatics items in the last category consist of Item 34 (navigating the electronic health record) to Item 35 (utilizing clinical technologies such as smart pumps and monitors). The possible responses for each question on the competency questionnaire were: 1 = Beginning, 2 = Developing, 3 = Accomplished. For each participant, the sums were obtained from each section and averaged over the students for both pre- and post-surveys.

The Preceptorship Experience Questionnaire was a selfadministered 67-item instrument that evaluated students' opinion and competency statements regarding their clinical nursing experiences. ${ }^{[35]}$ This instrument was content analyzed by three faculty teaching senior nursing courses after pilot studies. ${ }^{[35]}$ The first 12 questions evaluated student opinions of the program, and the second 43 questions evaluated student competency levels on the nursing processes that 
consisted of assessment, planning, implementation, evaluation, and professional growth and development. The opinion responses (i.e., "I feel it is important to have a primary preceptor in the clinical agency") were on a Likert scale ( $1=$ not important, 2 = somewhat important, $3=$ important, 4 $=$ moderately Important, 5 = very important). Cronbach's alpha, a measure of internal consistency, for the 12 opinion questions on the post-program survey was 0.91 . The competency responses (i.e., "I feel I have the competence to identify and assess patients' healthcare needs") were also on a Likert scale ( $1=$ not competent, 2 = less competent, 3 = competent, $4=$ moderately competent, 5 = very competent). Cronbach's alpha for the post-program responses was 0.98. Demographic data included 12 questions that asked participants' age, gender, ethnicity, type of program attended, clinical placement site, etc. at the end of this instrument.

The Graduate Nurse Experience Survey ${ }^{[36]}$ had 23 questions that addressed confidence levels of participants during the residency program. The responses were on a five-point Likert scale $(1=$ strongly disagree, 2 = disagree, 3 = neutral, $4=$ agree, and $5=$ strongly agree). Responses to questions that were negatively phrased were transformed so that the scale was consistent with the responses to the positively phrased questions. The survey had reliability coefficients of 0.78 to 0.92 for students experiencing preceptorship and residency programs. ${ }^{[36]}$

We analyzed data using descriptive and inferential statistics to evaluate clinical competence and confidence levels of participants. Student's $t$-test compared the pre-program averages with the post-program averages. Spearman rho assessed the relationship between demographic variables such as type of program attended (AA, BS, or MS degree) and clinical placement site (medical, surgical, maternity, pediatrics, etc.) and QSEN competency skills, and one way multivariate analysis of variance (MANOVA) examined the effects of the type of program attended and clinical placement sites on post-QSEN competency scores. Cronbach's alpha was used as a measure of internal consistency. Bonferroni's adjustment for multiple comparisons was used to adjust the level of significance. Summary statistics are reported in the Results section.

\section{Results}

Participants' age ranged from 22 to 61 years with a mean age of 29 years $(n=114)$. There were $97(84 \%)$ females and $17(16 \%)$ males. The majority $(n=91)$ of participants graduated from the BSN programs; and of those, 78 participants graduated from the public state university. Approximately $72 \%(\mathrm{n}=81)$ of the participants did not have jobs more than 12 months after graduation. With much help of clinical placement coordinators at each clinical site, participants were placed on various nursing units of the acute- and sub-acute care settings. The majority of participants $(n=75 \%)$ worked the day shift; and clinical units were medical surgical units (57\%), emergency (14\%), intensive care (13\%), maternity $(9 \%)$, pediatrics $(4 \%)$, rehabilitation $(2 \%)$, and community health nursing $(2 \%)$. Each participant worked with the assigned preceptor for the minimum of 288 hours over the 12-15 week period, average working 24-32 hours each week. Table 1 provides demographic characteristics of participants.

Table 1. Demographic characteristics of newly licensed residency participants $(n=114)$

\begin{tabular}{|c|c|c|}
\hline Demographic variables & Number (n) & Percentage (\%) \\
\hline \multicolumn{3}{|l|}{ Age } \\
\hline $20-29$ & 57 & 50 \\
\hline $30-39$ & 35 & 30 \\
\hline $40-49$ & 15 & 13 \\
\hline $50-59$ & 8 & 7 \\
\hline $60-61$ & 1 & 1 \\
\hline \multicolumn{3}{|l|}{ Gender } \\
\hline Female & 97 & 85 \\
\hline Male & 17 & 15 \\
\hline \multicolumn{3}{|l|}{ Education } \\
\hline $\mathrm{ADN}$ & 9 & 8 \\
\hline BSN & 91 & 80 \\
\hline MSN & 14 & 12 \\
\hline \multicolumn{3}{|l|}{ Ethnic Background } \\
\hline Asian & 49 & 43 \\
\hline Black & 7 & 6 \\
\hline Caucasian & 38 & 33 \\
\hline Hispanic & 12 & 11 \\
\hline Missing & 8 & 7 \\
\hline \multicolumn{3}{|c|}{ Months without Nursing Job } \\
\hline 6 month & 28 & 25 \\
\hline 10 month & 5 & 4 \\
\hline 12 month & 28 & 25 \\
\hline 15 month & 36 & 32 \\
\hline 24 month & 10 & 9 \\
\hline 27 month & 7 & 6 \\
\hline \multicolumn{3}{|l|}{ Clinical Placement } \\
\hline Emergency Department & 16 & 14 \\
\hline ICU/CCU & 15 & 13 \\
\hline Medical & 37 & 32 \\
\hline Surgical & 28 & 25 \\
\hline Maternity & 10 & 9 \\
\hline Pediatrics & 4 & 4 \\
\hline Rehab & 2 & 2 \\
\hline Community Health & 2 & 2 \\
\hline \multicolumn{3}{|c|}{ Clinical Residency Work Shift } \\
\hline 8 hour Day & 57 & 50 \\
\hline 12 hour Day & 28 & 25 \\
\hline 8 hour evening (PM) & 7 & 6 \\
\hline 8 hour Night & 2 & 2 \\
\hline 12 hour Night & 12 & 11 \\
\hline Rotating Shift & 8 & 7 \\
\hline
\end{tabular}

3.1 Quality and safety competency questionnaire results For each student, the sums were obtained from each of the seven sections and averaged over the students for both pre(before the program) and post- (after the program) surveys. The pre- and post-averages over students were compared 
using $t$-tests. In all cases (the sum of seven sections and the overall sum), the post-sums were significantly higher than the pre sums with all $p$-values being less than .001. This indicates that the students assessed themselves to be more competent after the program. Table 2 displays the summary statistics and $95 \%$ confidence intervals for the difference in average-sum (post minus pre). The average response per question is also cited in Table 2 for each section; the average increase per question (evaluated by section) ranged from 0.53 to 0.73 with an overall average of 0.62 increases in response per question. Students scored the highest on informatics with a mean of 2.93 , followed by quality improvements with a mean of 2.92; and lowest on patient centered care with a mean of 2.67 on their post survey. Compared to the pre data, students' post data showed the most improvement on quality improvements with the increase of 0.73 , followed by safety (0.66) and informatics (0.66), and least improvement on teamwork (0.53) and professionalism (0.54). Internal consistency, as measured by Cronbach's alpha, was 0.983 for all 36 questions of the Quality and Safety Competency Questionnaire.

A one-way multivariate analysis of variance (MANOVA) was calculated examining the effect of the type of program attended (AA, BS, or MS degree) on post-QSEN competency scores of patient centered care, safety, evidence based practice, teamwork, professionalism, quality improvement, and informatics. A significant effect was found (Lambda $(24,244)=0.632, p=.002)$. Follow up univariate ANOVAs indicated that a teamwork section was significantly improved by the type of program attended $(\mathrm{F}(3,91)=7.139, p=.000)$. We also conducted a one-way MANOVA to examine the effect of clinical placemen areas on post-QSEN scores of patient centered care, safety, professionalism, evidence based practice, quality improvement, and informatics. However no significant effect was found (Lambda $(80,541)=0.383, p$ $=.261$ ) on clinical placement sites (ED, medical, surgical, maternity, pediatrics, etc.). No QSEN scores were significantly influenced by clinical placement areas as indicated by Wilks Lambda's result. We performed Tukey's HSD to determine the differences for clinical placement sites and type of programs using the post-hoc command. Table 3 and 4 display the summary results of a one way MANOVA.

To assess the relationship between variables such as type of program attended and clinical placement site and QSEN competency skills, Spearman rho correlation coefficients were performed. However there were no significant correlations found between these variables. To further examine the relationships, correlation coefficients were calculated between the individual items of QSEN competency questionnaire and variables given. Bonferonni's adjustment for multiple comparisons was used to adjust the level of significance. Although very low, there was a significant correlation between the type of program attended and one (i.e., conducting comprehensive physical and psychosocial health history) of the patient centered care items $(r=0.20, p<.035)$. Previous work experiences was significantly correlated with establishing rapport and communicating with inter-professionals of the teamwork items $(r=0.220, p<.02 ; r=0.206, p<$ $.03)$ and professionalism $(r=0.223, p<.019)$. One of the teamwork items was also significantly correlated with the clinical placement site $(r=.204, p=.033)$. Table 5 displays the correlation results.

Table 2. Comparison of pre- and post-program student self-assessment of competency skills

\begin{tabular}{|c|c|c|c|c|c|c|c|}
\hline \multirow[t]{2}{*}{ Section } & \multirow{2}{*}{$\begin{array}{l}\text { Number of } \\
\text { Questions }\end{array}$} & \multirow{2}{*}{$\begin{array}{l}\text { Average of } \\
\text { Sum } \\
\text { Pre }\end{array}$} & \multirow{2}{*}{$\begin{array}{l}\text { Average of } \\
\text { Sum } \\
\text { Post }\end{array}$} & \multirow[t]{2}{*}{$p$} & \multirow{2}{*}{$\begin{array}{l}\text { Difference } \\
\text { (Post - Pre) }\end{array}$} & \multicolumn{2}{|c|}{$\begin{array}{l}\text { 95\% Confidence Interval for true } \\
\text { Difference in Average Sum }\end{array}$} \\
\hline & & & & & & Lower & Upper \\
\hline $\begin{array}{l}\text { Patient Centered Care } \\
\text { (Per question Average) }\end{array}$ & 9 & $\begin{array}{l}18.66 \\
(2.07)\end{array}$ & $\begin{array}{l}24.00 \\
(2.67)\end{array}$ & $<.001$ & $\begin{array}{l}5.34 \\
(0.60)\end{array}$ & 3.38 & 7.30 \\
\hline $\begin{array}{l}\text { Safety } \\
\text { (Per question Average) }\end{array}$ & 5 & $\begin{array}{l}10.72 \\
(2.14)\end{array}$ & $\begin{array}{l}14 \\
(2.80)\end{array}$ & $<.001$ & $\begin{array}{l}3.28 \\
(0.66)\end{array}$ & 2.16 & 4.40 \\
\hline $\begin{array}{l}\text { Evidence Based Practice } \\
\text { (Per question Average) }\end{array}$ & 3 & $\begin{array}{l}6.57 \\
(2.19)\end{array}$ & $\begin{array}{l}8.49 \\
(2.83)\end{array}$ & $<.001$ & $\begin{array}{l}1.92 \\
(0.64)\end{array}$ & 1.05 & 2.79 \\
\hline $\begin{array}{l}\text { Teamwork \& Collaboration } \\
\text { (Per question Average) }\end{array}$ & 8 & $\begin{array}{l}18.00 \\
(2.25)\end{array}$ & $\begin{array}{l}22.22 \\
(2.78)\end{array}$ & $<.001$ & $\begin{array}{l}4.22 \\
(0.53)\end{array}$ & 2.54 & 5.90 \\
\hline $\begin{array}{l}\text { Professionalism } \\
\text { (Per question Average) }\end{array}$ & 6 & $\begin{array}{l}13.06 \\
(2.18)\end{array}$ & $\begin{array}{l}16.30 \\
(2.72)\end{array}$ & $<.001$ & $\begin{array}{l}3.24 \\
(0.54)\end{array}$ & 1.9 & 4.58 \\
\hline $\begin{array}{l}\text { Quality Improve } \\
\text { (Per question Average) }\end{array}$ & 2 & $\begin{array}{l}4.38 \\
(2.19)\end{array}$ & $\begin{array}{l}5.83 \\
(2.92)\end{array}$ & $<.001$ & $\begin{array}{l}1.45 \\
(0.73)\end{array}$ & 0.79 & 2.12 \\
\hline $\begin{array}{l}\text { Informatics } \\
\text { (Per question Average) }\end{array}$ & 2 & $\begin{array}{l}4.54 \\
(2.27)\end{array}$ & $\begin{array}{l}5.86 \\
(2.93)\end{array}$ & $<.001$ & $\begin{array}{l}1.32 \\
(0.66)\end{array}$ & 0.78 & 1.86 \\
\hline $\begin{array}{l}\text { Overall Competency Assessment } \\
\text { (Per question Average) }\end{array}$ & 36 & $\begin{array}{l}78.56 \\
(2.18)\end{array}$ & $\begin{array}{l}99.17 \\
(2.75)\end{array}$ & $\begin{array}{l}<.001 \\
<.001\end{array}$ & 20.61 & 3.74 & 14.49 \\
\hline
\end{tabular}

Note. Likert scale (1 = beginning, 2 = developing, 3 = accomplished). 
Table 3. Multivariate tests $\dagger$ to examine effects of the type of program attended and clinical placement site on post-QSEN competency

\begin{tabular}{|c|c|c|c|c|c|c|}
\hline Effect & & Value & $\mathbf{F}$ & Hypothesis df & Error df & Sig. \\
\hline \multirow{3}{*}{ Intercept } & Pillai’s Trace & .924 & $126.944^{\ddagger}$ & 8.000 & 84.000 & .000 \\
\hline & Wilks’ Lambda & .076 & $126.944^{\ddagger}$ & 8.000 & 84.000 & .000 \\
\hline & Hotelling's Trace & 12.090 & $126.944^{\ddagger}$ & 8.000 & 84.000 & .000 \\
\hline \multirow{3}{*}{ Clinical practice sites } & Pillai’s Trace & .817 & 1.035 & 80.000 & 728.000 & .401 \\
\hline & Wilks’ Lambda & .383 & 1.106 & 80.000 & 541.332 & .261 \\
\hline & Hotelling's Trace & 1.154 & 1.186 & 80.000 & 658.000 & .139 \\
\hline \multirow{3}{*}{ Type of program attended } & Pillai’s Trace & .410 & 1.703 & 24.000 & 258.000 & .024 \\
\hline & Hotelling's Trace & .517 & 1.781 & 24.000 & 248.000 & .016 \\
\hline & Roy’s Largest Root & .335 & $3.647^{\text {护 }}$ & 8.000 & 87.000 & .001 \\
\hline
\end{tabular}

† Design: Intercept + clinical practice area + type of program attended; + Exact statistic; $+\uparrow$ The statistic is an upper bound on $\mathrm{F}$ that yields a lower bound on the significance level.

Table 4. Tests of between-subjects, effects of the type of program attended on seven categories of QSEN competency

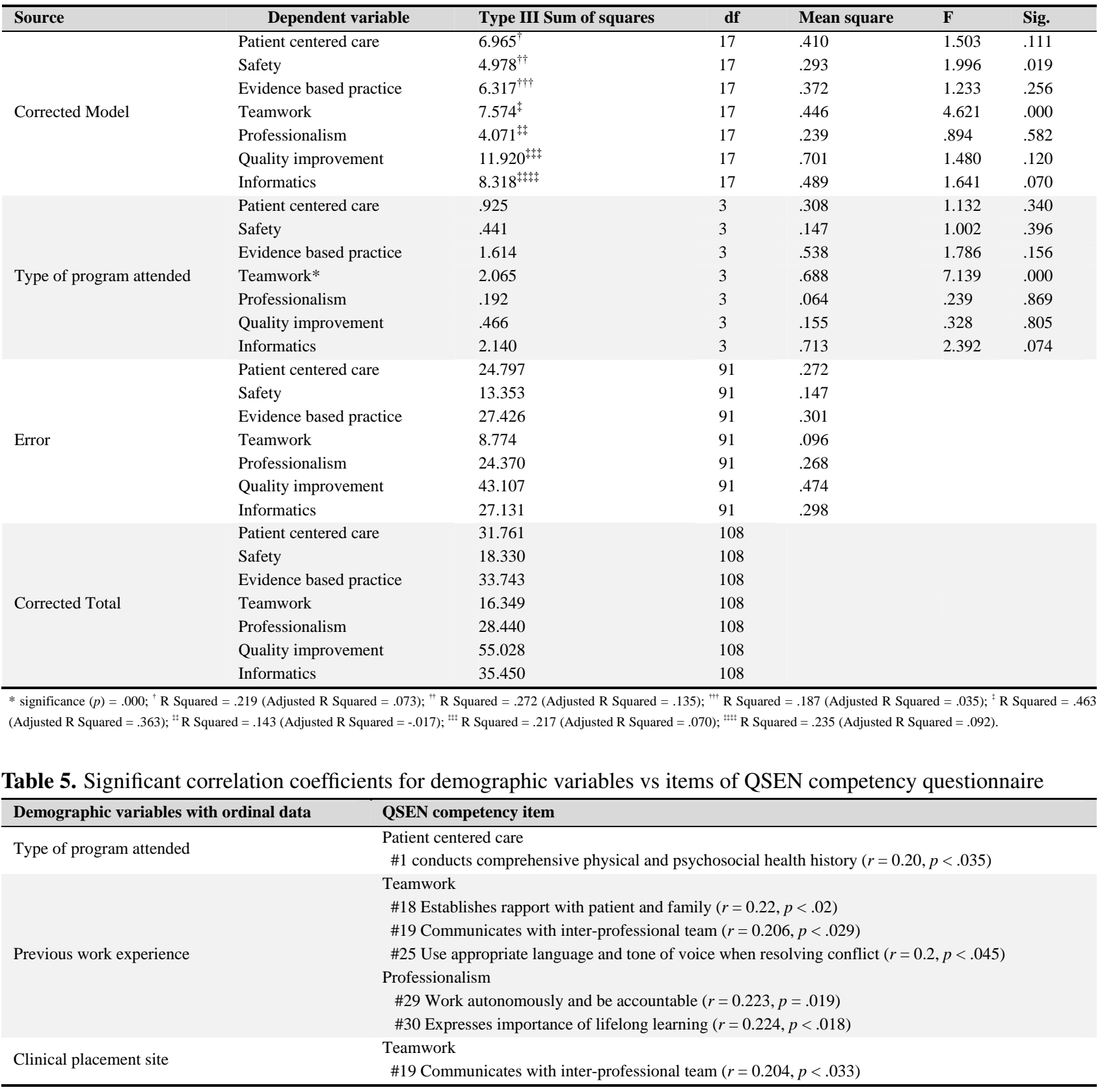




\subsection{Preceptorship experience questionnaire results}

The Preceptorship Experience Questionnaire has 12 items for assessing student opinion of the preceptorship program. The majority of the participants indicated that it was "important to very important" to develop a positive relationship with staff members on units (95\%) and trusting relationship with their preceptor (94\%); and have a primary preceptor (90\%) on their unit. Table 6 below summarizes the post-program opinions. Internal consistency as measured by Cronbach's alpha for this part of the survey was 0.91 .

Table 6. Summary for preceptorship experience questionnaire opinion items: Post-program data $(\mathrm{n}=114)$

\begin{tabular}{lllll}
\hline Opinion statement: “I feel it is important to:” & $\begin{array}{l}\text { Important to } \\
\text { Very Important (\%) }\end{array}$ & $\begin{array}{l}\text { Somewhat } \\
\text { Important (\%) }\end{array}$ & $\begin{array}{l}\text { Not Important } \\
\text { (\%) }\end{array}$ & $\begin{array}{l}\text { Missing: not } \\
\text { used in percent }\end{array}$ \\
\hline Have a primary preceptor in clinical area & $103(90 \%)$ & $8(7 \%)$ & $1(0.9 \%)$ & 2 \\
Develop a trusting relationship with their Preceptor & $107(94 \%)$ & $5(4 \%)$ & $0(0 \%)$ & 2 \\
Develop positive relationship with staff and others & $108(95 \%)$ & $4(3.5 \%)$ & $0(0 \%)$ & 2 \\
Evaluate strengths and weaknesses with Preceptor & $104(91 \%)$ & $7(6 \%)$ & $1(0.9 \%)$ & 2 \\
\hline
\end{tabular}

Note. Likert scale $(1=$ not important to 5 = very important $)$

The Preceptorship Experience Questionnaire addresses 43 questions for assessing perceived competency levels of the nursing process cycles: Assessment, planning, implementation, and evaluation as well as professional growth and development. Examples of items include competency identifying patients' healthcare needs, cultural needs in providing appropriate nursing care and learning needs. The sum of the 43 competency questions was averaged across students; and averages across students were compared for pre-program versus post-program. Thus each student obtained a competencysum, both pre-program and post-program, summing up the responses to the 43 questions. The difference in average perstudent-sum between pre-program and post-program was significant $(p$-value $=.003)$. The average response across ques- tions was 3.30 for pre-program and 4.02 for post-program. This indicates that on the average the students felt more competent after the program shifting towards "very competent". Results are shown in Table 7. The variables were categorized into the following nursing process cycles: Assessment (12 items), planning (4 items), implementation (16 items), evaluation (4 items) and professional growth and development (7 items). Pre- and post-program sums were compared. All comparisons were significant showing that the students felt significantly more competent after the program $(p<.012)$. The per-item averages increased by 0.72 to 0.89 points for all categories except Assessment which increased by 0.52 points.

Table 7. Comparison of pre-program versus post-program competency sum of preceptorship experience data $(\mathrm{n}=114)$

\begin{tabular}{|c|c|c|c|c|c|c|c|}
\hline \multirow[t]{2}{*}{ Section } & \multirow{2}{*}{$\begin{array}{l}\text { Number } \\
\text { of Items }\end{array}$} & \multirow{2}{*}{$\begin{array}{l}\text { Average of } \\
\text { Sum } \\
\text { Pre }\end{array}$} & \multirow{2}{*}{$\begin{array}{l}\text { Average of } \\
\text { Sum } \\
\text { Post }\end{array}$} & \multirow[t]{2}{*}{$p$} & \multirow{2}{*}{$\begin{array}{l}\text { Difference (Post } \\
\text { - Pre)/Average } \\
\text { per item }\end{array}$} & \multicolumn{2}{|c|}{$\begin{array}{l}\text { 95\% Confidence Interval for } \\
\text { true Difference in Average Sum }\end{array}$} \\
\hline & & & & & & Lower & Upper \\
\hline Assessment & 12 & 35.2 & 41.4 & .050 & $6.2 / 0.52$ & 0.02 & 7.24 \\
\hline Planning & 4 & 14.5 & 17.5 & .009 & $3.00 / 0.75$ & 0.46 & 4.31 \\
\hline Implementation & 16 & 54.1 & 65.6 & .001 & $11.5 / 0.72$ & 3.65 & 13.21 \\
\hline Evaluation & 4 & 13.5 & 16.5 & .005 & $3.00 / 0.75$ & 0.60 & 4.31 \\
\hline Prof Growth and Development & 7 & 25.6 & 31.8 & .006 & $6.2 / 0.89$ & 0.90 & 7.25 \\
\hline Overall Competency Assessment & 43 & 142.9 & 172.8 & .003 & 28.30/0.66 & 6.49 & 36.32 \\
\hline (Per question Average) & & $(3.30)$ & $(4.02)$ & .012 & & & \\
\hline
\end{tabular}

Note. Likert scale $(1=$ not competent to 5 = very competent $)$

\subsection{Graduate nurse experience survey results}

The Graduate Nurse Experience Survey consists of 23 questions which address confidence of newly licensed nurses. The majority of the questions were phrased positively, such as "strongly agree" indicating a high level of confidence. Examples of the items include: "I feel confident communicating with physicians; and I am having difficulty organizing patient care needs." The few questions that were phrased negatively, such as "strongly disagree" indicating a lack of confidence, were transformed to the positive scale. To address confidence levels of participants, the average per-student-sum was compared between the pre-program and post-program. The average response across questions was 3.56 for pre-program and 3.85 for post-program. This indicates that on the average 
the students felt more confident after the program, shifting towards confident from neutral responses. The results are shown in Table 8 below. Cronbach's alpha, a measure of internal consistency, was 0.81 for these 23 questions.

\subsection{Subjective data results}

The Quality and Safety Competency Questionnaire and Preceptorship Experience Survey contained a section for student comments. Substantial numbers of the students indicated that their critical thinking, problem solving, professionalism, team building, safety, and medication management skills improved after the residency program. For example, frequently occurred comments of participants included as followings: "Improved my critical thinking skills and demonstrated safe practice in medication administration, pain management, and wound care; utilized the nursing processes comfortably to conduct the comprehensive physical and psychosocial assessment and provide safe and effective nursing care to my patients; applied SBAR communications and evidence based practice and collaborated with other interdisciplinary team members in developing nursing care and discharge plan; demonstrated professionalism, patient advocacy and multitasking during nursing practice on my unit; felt ready to work on my own if given the opportunity; gained more knowledge and confidence as a nurse now; felt competent to work as an emergency room nurse; would continue developing my assessment skills and time management responsibilities; met my goals by the end of my residency and would be able to care for a full patient load, communicate with physicians, and other team members;" and "thank you for the opportunity, I would continue to improve and refine my critical thinking and time management strategies."

Table 8. Comparison of the overall confidence levels of new graduate nurses pre and post residency program $(\mathrm{n}=114)$

\begin{tabular}{|c|c|c|c|c|c|c|c|}
\hline \multirow[t]{2}{*}{ Section } & \multirow{2}{*}{$\begin{array}{l}\text { Number of } \\
\text { questions }\end{array}$} & \multirow{2}{*}{$\begin{array}{l}\text { Average of } \\
\text { Sum } \\
\text { Pre }\end{array}$} & \multirow{2}{*}{$\begin{array}{l}\text { Average } \\
\text { of Sum } \\
\text { Post }\end{array}$} & \multirow[t]{2}{*}{$p$} & \multirow{2}{*}{$\begin{array}{l}\text { Difference } \\
\text { (Post - Pre) }\end{array}$} & \multicolumn{2}{|c|}{$\begin{array}{l}\text { 95\% Confidence Interval for } \\
\text { true Difference in Average Sum }\end{array}$} \\
\hline & & & & & & Lower & Upper \\
\hline
\end{tabular}

Note. Likert Scale $(1$ = strongly disagree to 5 = strongly agree)

\section{Discussion}

This study examines the perceptions of novice nurses who have participated in transition to practice experiences and evaluates the levels of their perceived competency implementing the QSEN core competency skills before and after the new RN residency program. The competency and confidence of participants in demonstrating the nursing process cycles including assessment, planning, implementation, and evaluation as well as professional role development are also evaluated. Results indicate that compared to the pre-program, novice nurses have perceived significantly higher levels of self-reported nursing competency skills after participating in the new RN residency program. For example, the pre- and post-averages of participants on the QSEN questionnaire that measures their core competency of nursing knowledge, skills, and attitudes of patient-centered care, safety, team work, evidence based practice, quality improvement, and informatics are compared using $t$-tests: In all cases, the post-sums show significantly higher levels than the pre-sums, indicating that the study participants have perceived themselves more competent carrying out nursing skills after the program. This outcome coincides with the study conducted by Sullivan, Hirst, and Cronenwett ${ }^{[37]}$ in that their study sample relatively have perceived high levels of preparedness in the nursing program that implemented the QSEN framework, implying skills' improvements; and participants have endorsed the importance of quality and safety competencies to professional practice after the program. Although literature provides the substantial numbers of recommendations for educators to use the QSEN framework in their nursing curriculum, there is a scarcity of literature that report research outcomes on investigating the effectiveness of core QSEN competency skills in students and their comprehensive applications to novice nurses.

Compared to the pre-program data, students have responded with an increased level of the post-program average per each QSEN category, indicating their perceived improvement in competency in nursing knowledge, skills and attitude. Of the seven categories, the quality improvement category shows the most increased average response, indicating that students may have felt better or improved in understanding quality improvement strategies. The teamwork and professionalism categories show the least average increase, indicating that students probably have opportunities for further development. However as stated, the overall responses of the post-program average are higher than the pre-program average, indicating the residency program could be an effective means of improving the participants' competency skills.

Demonstrated by the comparative analyses of one way 
MANOVA, the types of programs that students attended shows a significant effect on improving the teamwork category of QSEN competency. However no effects have been found on clinical placement sites, indicating QSEN scores are not significantly influenced by clinical placement areas where students conducted their clinical practice.

Results of correlational statistics indicate that there are no significant relationships between the overall QSEN competency score and demographic variables. However we have found several individual QSEN competency items that show significant correlations with the demographic variables, such as the type of program students attended and clinical placement sites although they are low in correlation. This indicates that the particular type of nursing program that students have attended and the clinical placement site might have influenced perceived competency skills reported by participants.

Substantial numbers of researchers have analyzed parts of the QSEN core concepts (i.e., safety or patient centered care) on their studies. For example, Ginsburg, Tregunno, and Norton $^{[38]}$ examined the self-reported patient safety part of QSEN competency of newly registered nurses and other healthcare practitioners. In their study, participants reported feeling more confident in learning the safety measures related to effective communication with patients and other healthcare providers. However, nurses' confidence in learning about working in teams with other health professions deteriorated as they moved from thinking about learning in the classroom to the clinical setting. ${ }^{[38]}$ This outcome contradicts with the current study in that participants in this study report that their perceived competency and confidence had increased in clinical settings after participating 12-15 weeks of the new RN residency program.

Students perceive that they are competent to very competent in demonstrating assessment, planning, implementation, and evaluation as well as professional role development skills. Based on the results, each comparison is significant and shows that the perceived levels of competency in students are significantly higher after the program. The increase in the per-item average is the highest on professional role development category, follow by evaluation, planning, and implementation. Students perceive to be most competent on professional role development skills such as; managing stress related to personal and professional situations, working effectively with healthcare team members to assure the comprehensive care has been delivered to patients; and coping effectively with their own feelings related to patients, coworkers, and supervisory personnel. Although there is a slight increase in the post-sum score, the assessment category shows the least increase, indicating students might have perceived that they had not improved this skill greatly after the program.

The implications of results shown in the previous section indicate that the competency in professional roles have significantly increased after the program. This outcome concurs with the study demonstrated by Lewallen and DeBrew ${ }^{[39]}$ which reported that students in a successful residency program demonstrated professional behaviors and skills, including being positive, the ability to adapt to the clinical setting, and building relationships with nursing staff. In fact, AlDossary, Kitsantas, and Maddox ${ }^{[25]}$ also concur with the study outcome in that they claim the transition program reduced the turnover in the first year of practice and promoted professional growth of the new graduates in competencies including hands-on nursing care, clinical decision making, and leadership skills.

The majority of participants report that it is very important to have a primary preceptor and develop a trusting relationship with them; participants also indicate that it is very important to develop a positive relationship with staff on the unit. This outcome is concurrent with a previous study conducted by $\mathrm{Kim}^{[35]}$ that reported the similar results. Myrick and Yonge $^{[40]}$ also reported that the relational process of specific preceptor behaviors, such as maintaining a trusting relationship, were pivotal to the enhancement of critical thinking of nursing students and ultimately impact on the success or failure of the clinical experience. An ongoing interpersonal dynamic between the student and preceptor is important for enhancing the critical thinking ability of new graduate nurses. However, the success in assisting students to improve nursing competency skills in assessment, planning, implementation, and evaluation, is not related to having only one primary nurse in the clinical agency.

To address the confidence level of participants, the average per-student-sum on the Graduate Nurse Experience Survey is utilized. The total confidence scale demonstrates that the post-sums are significantly higher than the pre-sums. This indicates that the students have perceived themselves to be more confident after the program. This outcome is concurrent with the study conducted by Rush, Adamack, Gordon, Janke, and Ghement ${ }^{[41]}$ in that their finding indicated that a formal orientation-transition program had significantly higher total confidence scores than nurses that did not participate in the program.

Written comments of students confirm that their critical thinking, problem solving, communication, team building, and medication management skills have improved after the residency program. For example, their comments reflect that they are better able to utilize the nursing process cycles for 
conducting the comprehensive physical and psychosocial assessments; provide a safe and effective nursing care to their patients; apply effective communications to solve the problems; and collaborate professionally with other healthcare team members in developing nursing care and discharge plans at the end of the residency program.

\section{Limitations}

Although a sample comprise of new graduate nurses from the ADN, BSN, and MSN programs, the limitations of the study might include the use of a sample from only one school site. This might have captured additional ideas if students from a greater number of nursing programs are considered. A second limitation is variables that are beyond control, including the diversity of assigned preceptors, individual students' work experiences, and different clinical specialty placements resulting in different clinical experiences. Further research in these areas that increase types of nursing programs and additional geographical representation is warranted. Additionally, research using both expert preceptors and new graduates may provide additional information that would be valuable for the residency program.

\section{Conclusion}

The residency program provides novice nurses with the opportunity to gain the nursing knowledge, skills, and attitudes necessary for carrying out quality and safe patient care, utilizing the nursing process cycles. It also benefits students by improving clinical competence, confidence, and socialization skills. Results of the overall study have shown that novice nurses perceived the higher levels of nursing competency skills and confidence over time. Findings also suggest that a majority of the students have perceived that it is important to develop a trusting relationship with their preceptor and a positive relationship with staff nurses. Students feel their competency levels improved significantly in the areas of quality improvements, informatics, safety, and evidence based practice. Importantly, novice nurses perceive that they have developed professional roles and socialization skills as well.

In conclusion, the study findings provide important information about the success of the residency program that facilitated the transition of the critical period between education and competent practice for newly graduated nurses. The information obtained may be useful for nursing educators continuing to strive and reconcile the lack of preparedness that is mentioned by many employers in new graduates who are transitioning into staffing roles.

\section{ACKNOWLEDGEMENTS}

Funding for this study was provided by the Alameda County Workforce Investment Board, Gordon and Betty Moore Foundation via CINHC, and East Bay Community Foundation in Alameda County. We thank the Bay Area nursing preceptors and clinical placement coordinators for their time and expertise, and new graduate nurses for their participation in the study.

\section{CONFLICTS OF INTEREST DisClosure}

The authors declare that there is no conflict of interest statement.

\section{REFERENCES}

[1] Brewer CS, Kovner CT, Yingrengreung S, et al. Original research: New nurses, has the recession increased their commitment to their jobs? American Journal of Nursing. 2012; 112(3): 34 44. PMid:22333970 http://dx.doi.org/10.1097/01. NAJ.00 $00412637.63022 . d 4$

[2] Nicely KL, Fairman J. Postgraduate nurse practitioner residency programs: Supporting transition to practice. Academic Medicine: Journal of Association of American Medical Colleges. 2014. PMid:25551860 http://dx.doi.org/10.1097/ACM. 000 0000000000567

[3] Currey J, Oldland E, Considine J, et al. Evaluation of postgraduate critical care nursing students' attitudes to, and engagement with, team-based learning: A descriptive study. Intensive \& Critical Care Nursing. 2015; 31(1): 19-28. PMid:25439141 http: //dx.doi.org/10.1016/j.iccn.2014.09.003

[4] Fiedler R, Read ES, Lane KA, et al. Long-term outcomes of a postbaccalaureate nurse residency program: A pilot study. The Journal of Nursing Administration. 2014; 44(7/8): 417-422. PMid:25072232 http://dx.doi.org/10.1097/NNA. 0000000000000092

[5] Wyte-Lake T, Tran K, Bowman CC, et al. A systematic review of strategies to address the clinical nursing faculty shortage. Journal of Nursing Education. 2013; 52(5): 245-252. PMid:23402282 http://dx.doi.org/10.3928/01484834-20130213-02

[6] Anderson T, Linden L, Allen M, et al. New graduate RN work satisfaction after completing an interactive nurse residency. Journal of Nursing Administration. 2009; 39(4): 165-169. PMid:19359887 http://dx.doi.org/10.1097/NNA.0b013e31819c9cac

[7] Goode CJ, Lynn MR, Krsek C, et al. Nurse residency programs: An essential requirement for nursing. Nursing Economic\$. 2009; 27(3): 142-147. PMid: 19558074

[8] Bratt MM. Retaining the next generation of nurses: The Wisconsin nurse residency program provides a continuum of support. Journal of Continuing Education in Nursing. 2009; 40(9): 416-425. PMid:19754029 http://dx.doi.org/10.3928/00220124-200 90824-05

[9] Dracup K, Morris PE. Nurse residency programs: Preparing for the next shift. 2007, American Journal of Critical Care. 2007; 16 : 328-330. PMid:17595356

[10] Kumaran S, Carney M. Role transition from student nurse to staff nurse: Facilitating the transition period. Nurse Education in Prac- 
tice. 2014; 14(6): 605-611. http://dx.doi.org/10.1016/j.n epr.2014.06.002

[11] Mellor P, Greenhill JA. patient safety focused registered nurse transition to practice program. Contemporary Nurse. 2014; 47(1-2): 51-60. PMid:25267127 http://dx.doi.org/10.1080/1037617 8.2014.11081906

[12] Bratt MM, Felzer HM. Predictors of new graduate nurses' organizational commitment during a nurse residency program. Journal of Nurses Staff Development. 2012; 28(3): 108-119. PMid:22617781 http://dx.doi.org/10.1097/NND. 0b013e31825515c4

[13] Kovner CT, Brewer CS, Fatehi F, et al. What does nurse turnover rate mean and what is the rate? Policy, Politics, \& Nursing Practice. 2014 Aug 25. PMid:25156041 http://dx.doi.org/10.1177/1527154414547953

[14] Arnold J. Cost of hiring new nurses. Advance Healthcare for Nurses. 2012; Available from: http://nursing.advanceweb.com/Fea tures/Articles/Cost-of-Hiring-New-Nurses .aspx

[15] Glynn P, Silva S. Meeting the needs of new graduates in the emergency department: A qualitative study evaluating a new graduate internship program. Journal of Emergency Nursing. 2013; 39(2): 173-178. http://dx.doi.org/10.1016/j.jen.2011.10.007

[16] Scott ES, Engelke MK, Swanson M. New graduate nurse transitioning: Necessary or nice? Applied Nursing Research. 2008; 22(2): 75-83. PMid:18457746 http://dx.doi.org/10.1016/j . apnr . 2006.12.002

[17] Banister G, Bowen-Brady HM, Winfrey ME. Using career nurse mentors to support minority nursing students and facilitate their transition to practice. Journal of Professional Nursing. 2014; 30(4): 317-325. PMid:25150417 http://dx.doi.org/10.1016/j . pro fnurs.2013.11.001

[18] Marcum EH, West RD. Structured orientation for new graduates: A retention strategy. Journal for Nurses in Staff Development. 2004; 20(3): 118-124. http://dx.doi.org/10.1097/00124645-200 405000-00003

[19] Newhouse RP, Hoffman JJ, Suflita J, et al. Evaluating an innovative program to improve new nurse graduate socialization into the acute healthcare setting. Nursing Administration Quarterly. 2007; 31(1): 50-60. http://dx.doi.org/10.1097/00006216-20070 1000-00013

[20] Adams JM, Alexander GA, Chisari RG, et al. Strengthening new graduate nurse residency programs in critical care: Recommendations from nurse residents and organizational stakeholders. Journal of Continuing Education in Nursing. 2014; 1-8. http://dx . doi .o $\mathrm{rg} / 10.3928 / 00220124-20151217-01$

[21] Fink R, Krugman M, Casey K, et al. The graduate nurse experience: Qualitative residency program outcomes. Journal of Nursing Administration. 2008; 38(7/8): 341-348. PMid:18690125 http: //dx.doi.org/10.1097/01. NNA.0000323943.82016.48

[22] Rush KL, Adamack M, Gordon J, et al. Best practices of formal new graduate nurse transition programs: an integrative review. International Journal of Nursing Studies. 2013; 50(3): 345356. PMid:22795800 http://dx.doi.org/10.1016/j.ijnurst u. 2012.06.009

[23] Matua GA, Seshan V, Savithri R, et al. Challenges and strategies for building and maintaining effective preceptor-preceptee relationships among nurses. Sultan Qaboos University Medical Journal. 2014; 14(4): 530-536.

[24] Beecroft PC, Santner S, Lacy ML, et al. New graduate nurses' perceptions of mentoring: Six-year program evaluation. Journal of Advanced Nursing. 2006; 55(6): 736-747. http://dx.doi.org/10. $1111 / j .1365-2648.2006 .03964 . x$
[25] Al-Dossary R, Kitsantas P, Maddox PJ. The impact of residency programs on new nurse graduates' clinical decision-making and leadership skills: A systematic review. Nurse Educator Today. 2014; 34(6): 1024-1028. PMid:24183633 http://dx.doi.org/10.10 $16 / j$.nedt. 2013.10.006

[26] Beyea SC, von Reyn L, Slattery MJ. A nurse residency program for competency development using human patient simulation. Journal for Nurses in Staff Development. 2007; 23(2): 77-82. PMid:17414857 ht tp://dx.doi.org/10.1097/01.NND.0000266613.16434.05

[27] Pine R, Tart K. Return on investment: Benefits and challenges of a baccalaureate nurse residency program. Nursing Economic\$. 2007; 25(1): 13-18, 39. PMid:17402673

[28] Winfield C, Melo K, Myrick F. Meeting the challenge of new graduate role transition: Clinical nurse educators leading the change. Journal for Nurses in Staff Development. 2009; 25(2): E7-E13. PMid:19346825 http://dx.doi.org/10.1097/NND.0 b013e31819c76a3

[29] Halfer D, Graf E, Sullivan C. The organizational impact of a new graduate pediatric nurse mentoring program. Nursing Economic\$. 2008; 26(4): 243-249. PMid:18777973

[30] Halfer D. A magnetic strategy for new graduate nurses. Nursing Economic\$. 2007; 25(1): 6-11. PMid: 17402672

[31] Williams CA, Goode CJ, Krsek C, et al. Post-baccalaureate nurse residency 1-year outcomes. Journal of Nursing Administration. 2007; 37(7/8): 357-365. PMid:17939467 http://dx.doi.org/10.1097 /01. NNA.0000285112.14948.0f

[32] Kowalski S, Cross CL. Preliminary outcomes of a local residency program for new graduate registered nurses. Journal of Nursing Management. 2010; 18: 96-104. PMid:20465735 http://dx.doi.org /10.1111/j.1365-2834.2009.01056.x

[33] Bay Area Transition Program Committee. Quality and safety education for nurses (QSEN) evaluation short form, CINHC, CA: Unpublished Document: 2010.

[34] Cronenwett L, Sherwood G, Barnsteiner J, et al. Quality and safety education for nurses. Nursing Outlook. 2007; 55(3): 122131. PMid:17524799 http://dx.doi.org/10.1016/j.outlook .2007 .02 .006

[35] Kim K. Perceived competency of senior nursing students after their clinical preceptorship programs. Journal of Professional Nursing. 2007; 23(6): 369-375. http://dx.doi.org/10.1016/j.profn urs. 2007.01.019

[36] Casey K, Fink R. Casey-Fink graduate nurse experience survey (revised version), CO: University of Colorado Hospital Press: 2006.

[37] Sullivan DT, Hirst D, Cronenwett L. Assessing quality and safety competencies of graduating prelicensure nursing students. Nurse Outlook. 2009; 57(6): 323-331. PMid:19942033 http://dx.doi.org /10.1016/j.outlook.2009.08.004

[38] Ginsburg LR, Tregunno D, Norton PG. Self-reported patient safety competence among new graduates in medicine, nursing and pharmacy. 2013; 22(2): 147-54. http://dx.doi.org/10.1136/bmj qs-2012-001308

[39] Lewallen LP, DeBrew JK. Successful and unsuccessful clinical nursing students. Journal of Nurse Educator. 2012; 51(7): 389-395. PMid:22533497 http://dx.doi.org/10.3928/01484834-201 20427-01

[40] Myrick F, Yonge O. Preceptor behaviors integral to the promotion of student critical thinking. 2012; 18(3): 127-133.

[41] Rush KL, Adamack M, Gordon J, et al. Orientation and transition program component predictors of new graduate workplace integration. Journal of Nursing Management. 2013 Jul 5. http: //dx.doi.org/10.1111/jonm.12106 